\title{
Neuroimaging in Alzheimer's disease: current role in clinical practice and potential future applications
}

\author{
Luiz Kobuti Ferreira, Geraldo F. Busatto \\ Laboratory of Psychiatric Neuroimaging (LIM-21), Institute of Psychiatry, Faculdade de Medicina, Universidade de São Paulo, São Paulo, SP, Brazil.
}

\begin{abstract}
Alzheimer's disease is the most common cause of dementia and its prevalence is expected to increase in the coming years. Therefore, accurate diagnosis is crucial for patients, clinicians and researchers. Neuroimaging techniques have provided invaluable information about Alzheimer's disease and, owing to recent advances, these methods will have an increasingly important role in research and clinical practice. The purpose of this article is to review recent neuroimaging studies of Alzheimer's disease that provide relevant information to clinical practice, including a new modality: in vivo amyloid imaging. Magnetic resonance imaging, single photon emission computed tomography and ${ }^{18} \mathrm{~F}$-fluorodeoxyglucose-positron emission tomography are currently available for clinical use. Patients with suspected Alzheimer's disease are commonly investigated with magnetic resonance imaging because it provides detailed images of brain structure and allows the identification of supportive features for the diagnosis. Neurofunctional techniques such as single photon emission computed tomography and ${ }^{18} \mathrm{~F}$-fluorodeoxyglucosepositron emission tomography can also be used to complement the diagnostic investigation in cases of uncertainty. Amyloid imaging is a non-invasive technique that uses positron emission tomography technology to investigate the accumulation of the $\beta$-amyloid peptide in the brain, which is a hallmark of Alzheimer's disease. This is a promising test but currently its use is restricted to very few specialized research centers in the world. Technological innovations will probably increase its availability and reliability, which are the necessary steps to achieve robust clinical applicability. Thus, in the future it is likely that amyloid imaging techniques will be used in the clinical evaluation of patients with Alzheimer's disease.
\end{abstract}

KEYWORDS: Alzheimer's disease; Neuroimaging; Amyloid imaging; Diagnosis; Classification.

Ferreira LK, Busatto GF. Neuroimaging in Alzheimer's disease: current role in clinical practice and potential future applications. Clinics. 2011;66(S1):19-24.

Received for publication on March 15, 2011; Accepted for publicaiton on March 16, 2011

E-mail: kobuti@yahoo.com / gbusatto@terra.com.br

Tel.: 551130697651

\section{INTRODUCTION}

Alzheimer's disease (AD) is the most common cause of dementia in the general population. Clinical diagnosis of $\mathrm{AD}$ is based on a history of progressive and characteristic cognitive decline and the presence of objective cognitive deficits. Exclusion of other diagnoses such as depression, hypothyroidism, other dementias and non-AD brain lesions is an integral part of the diagnostic evaluation. ${ }^{1}$ Since AD is the most common type of dementia and its burden is expected to grow substantially owing to aging of the population, improving the diagnostic accuracy of $\mathrm{AD}$ is critical.

Neuroimaging examinations are an essential part of the diagnostic investigation of dementia. These examinations are important not only to identify non-AD pathological processes that can lead to cognitive decline (e.g. brain tumors or cerebrovascular disease) but also to search for biological markers that provide supportive features for the diagnosis of AD. These include medial temporal lobe atrophy as assessed with magnetic resonance imaging (MRI) and reduced glucose metabolism in temporoparietal

Copyright (c) 2011 CLINICS - This is an Open Access article distributed under the terms of the Creative Commons Attribution Non-Commercial License (http:// creativecommons.org/licenses/by-nc/3.0/) which permits unrestricted noncommercial use, distribution, and reproduction in any medium, provided the original work is properly cited. regions on functional neuroimaging with ${ }^{18} \mathrm{~F}$-fluorodeoxyglucose-positron emission tomography (FDG-PET). ${ }^{2}$

Though there is no test to diagnose AD accurately in vivo, in the past few years advances in neuroimaging technology have changed our understanding of AD. This review will focus on recent neuroimaging studies of AD that provide relevant information to clinical practice. We will also examine a new neuroimaging modality - amyloid imaging - and discuss whether such technique can be combined with innovative methods of data processing and analysis to improve AD diagnostic accuracy.

\section{NEUROIMAGING AND AD: UNDERSTANDING THE BRAIN CHANGES UNDERLYING THE SYMPTOMS OF THE DISEASE}

Over the past decades, many research investigations have applied neuroimaging techniques to gather information about the anatomical and functional brain changes related to AD. Table 1 summarizes the clinical utility of neuroimaging modalities used in patients with suspected AD.

Thanks to major improvements in image acquisition, processing and analysis, these studies have conducted detailed assessments of the human brain in vivo comparing groups of patients with dementia and unaffected elderly volunteers. A very brief summary of clinically relevant neuroimaging findings in samples of patients with $A D$ is presented in Table 2 . 
Table 1 - Neuroimaging modalities in patients with suspected Alzheimer's disease.

\begin{tabular}{|c|c|c|c|}
\hline Modality & Information afforded & Clinical utility in dementia & Current availability \\
\hline MRI & $\begin{array}{l}\text { Visualization of gray } \\
\text { matter, white matter } \\
\text { and cerebrospinal } \\
\text { fluid }\end{array}$ & $\begin{array}{l}\text { Important to identify non-Alzheimer's } \\
\text { disease etiologies } \\
\text { Useful to characterize supportive } \\
\text { features for the diagnosis of Alzheimer's } \\
\text { disease (medial temporal lobe atrophy) }\end{array}$ & $\begin{array}{l}\text { Available in developed geographic } \\
\text { regions. Limited availability in } \\
\text { underdeveloped areas }\end{array}$ \\
\hline СT & $\begin{array}{l}\text { Identification of gross } \\
\text { brain abnormalities }\end{array}$ & $\begin{array}{l}\text { Identification of large lesions. Useful if there are } \\
\text { contraindications for magnetic resonance imaging }\end{array}$ & Widely available \\
\hline FDG-PET & $\begin{array}{l}\text { Regional brain glucose } \\
\text { metabolism }\end{array}$ & $\begin{array}{l}\text { Useful in cases of diagnostic uncertainty despite } \\
\text { a thorough evaluation }{ }^{12} \\
\text { SPECT/FDG-PET should not be used as the only } \\
\text { imaging measure }\end{array}$ & Limited to specialized centers \\
\hline SPECT & Regional brain perfusion & & \\
\hline $\begin{array}{l}\text { Amyloid imaging } \\
\text { with PET }\end{array}$ & $\begin{array}{l}\text { Identification of amyloid } \\
\text { deposition in the brain }\end{array}$ & $\begin{array}{l}\text { In the future may be used as a very sensitive } \\
\text { (though nonspecific) test for Alzheimer's disease }\end{array}$ & $\begin{array}{l}\text { Only in a very few specialized } \\
\text { research centers in the world }\end{array}$ \\
\hline
\end{tabular}

$\mathrm{CT}=$ computed tomography; $\mathrm{FDG}-\mathrm{PET}={ }^{18} \mathrm{~F}$-fluorodeoxyglucose-positron emission tomography; $\mathrm{MRI}=$ magnetic resonance imaging; $\mathrm{SPECT}=$ single photon emission computed tomography.

MRI has become the most used tool for cerebral imaging in vivo for the assessment of dementia, as it provides detailed information about brain structure, thus allowing the characterization of regional brain atrophy and the identification of causes for the cognitive decline, such as white matter lesions, cerebral infarcts and brain tumors. Conversely, computed tomography (CT) investigations are seldom part of the outpatient diagnostic work-up of cognitive complaints owing to its lower spatial resolution. Notwithstanding, CT can be used in cases of contraindications for MRI (e.g. pacemaker). MRI is used to evaluate the anatomical features of the brain because it provides a clear distinction between gray matter, white matter and cerebrospinal fluid. The most consistent findings in MRI studies of patients with AD are atrophy in the medial temporal lobe (hippocampus, amygdala, entorhinal cortex and parahippocampal gyrus), ventricular enlargement and smaller total brain volume. ${ }^{3,4}$ MRI data have also been used to compare AD with other neurodegenerative conditions, such as dementia with Lewy bodies, frontotemporal lobar degeneration and Parkinson's disease dementia. Despite some heterogeneity in the results of these studies, they provide consistent evidence for the presence of a characteristic pattern of gray matter atrophy in AD involving mainly the medial temporal lobe, insula and temporoparietal cortices. ${ }^{3}$

The dynamics of atrophy in AD has been assessed by cross-sectional and longitudinal MRI studies. Initially, atrophy is most pronounced in the medial temporal lobe; ${ }^{3}$

Table 2 - Clinically relevant neuroimaging findings in patients with Alzheimer's disease.

\begin{tabular}{lc}
\hline Imaging Modality & Major findings in Alzheimer's disease \\
\hline MRI & $\begin{array}{c}\text { Gray matter atrophy beginning in the } \\
\text { medial temporal lobe and progressing } \\
\text { to the temporal neocortex, parietal } \\
\text { cortex and frontal cortex }\end{array}$ \\
& Hypometabolism/hypoperfusion in \\
FDG-PET and SPECT & temporoparietal cortex \\
DTI & Loss of white matter integrity in limbic \\
& and cortico-cortical tracts \\
Amyloid imaging & Amyloid deposition in the cortex \\
\hline
\end{tabular}

$\mathrm{DTI}=$ diffusion tensor imaging; FDG-PET $={ }^{18} \mathrm{~F}$-fluorodeoxyglucosepositron emission tomography; MRI = magnetic resonance imaging; SPECT $=$ single photon emission computed tomography. next, the temporal neocortex is involved; then, the atrophic pattern extends to the parietal and frontal lobes. ${ }^{5,6}$ These descriptions are in accordance with the results of previous neuropathological studies that examined postmortem brains of patients with different stages of AD. ${ }^{7}$

Since the pathological processes that lead to AD are known to begin years before the clinical syndrome, longitudinal studies have provided valuable information about the preclinical stages of $\mathrm{AD}$, such as mild cognitive impairment (MCI), a condition characterized by cognitive decline in the absence of clinical dementia. Recent metaanalyses have shown that gray matter atrophy is a consistent finding in elderly subjects with MCI and also that medial temporal lobe atrophy is a neurostructural biomarker of MCI conversion to AD. ${ }^{8,9}$

Neurofunctional imaging modalities, such as FDG-PET and regional cerebral blood flow imaging with single photon emission computed tomography (SPECT) provide, respectively, information about regional glucose metabolism and brain perfusion. Several research studies have evaluated samples of patients with AD relative to elderly controls using neurofunctional modalities such as FDG-PET and SPECT. The characteristic pattern found in AD is of hypometabolism/hypoperfusion in the temporoparietal cortex. ${ }^{10,11}$ A recent meta-analysis found that hypometabolism/hypoperfusion of the inferior parietal lobules and precuneus is the most consistent neurofunctional finding in AD in comparison with healthy elderly subjects. ${ }^{9}$ Moreover, longitudinal neurofunctional imaging studies have demonstrated hypometabolism/hypoperfusion in the parietal lobe of MCI converters in comparison with those who did not convert to AD. ${ }^{9}$ These functional imaging techniques can be useful in cases of diagnostic uncertainty despite thorough evaluation $^{12}$ and have been shown to be valuable to distinguish AD from frontotemporal dementia. ${ }^{13}$ However, they should not be used as the only imaging modality because they do not allow an adequate evaluation of brain structure. $^{14}$

A distinct regional finding resulting from neurostructural and neurofunctional imaging studies - respectively, medial temporal lobe atrophy and parietal hypoperfusion/hypometabolism - has been reported by authors who assessed patients with $\mathrm{AD}$ using both MRI and neurofunctional methods (FDG-PET or SPECT). ${ }^{15,16}$ The neurofunctional decline in the parietal lobe is thought to be due to a 
'diaschisis' effect, caused by disruption in the white matter bundles that connect the atrophic temporal lobe structures to the parietal lobe. ${ }^{16}$

White matter volume can also be measured with MRI. Studies comparing groups of patients with AD against elderly controls have found volumetric reduction in the corpus callosum, fornix and the cingulum bundle in AD samples. ${ }^{16,17}$ More subtle white matter abnormalities can be detected using a novel MRI technique called diffusion tensor imaging. By measuring water diffusivity, diffusion tensor imaging studies allow researchers to draw inferences about the integrity of white matter. ${ }^{18}$ In AD, widespread white matter disruption has been demonstrated, involving both limbic pathways (e.g. fornix) and cortico-cortical tracts (e.g. uncinate fasciculus and corpus callosum). ${ }^{19,20}$

Although a very important source of knowledge about the pathophysiology of the disease, the brain imaging modalities cited above have limited diagnostic utility because their findings are not specific to $\mathrm{AD}$ and they are not sufficiently sensitive to detect mild or preclinical disease stages. This is important not only to clinical practice but also to the development of new therapies: researchers seeking disease-modifying agents are aware that an efficient drug should ideally be started before patients present with overt dementia but, in order to choose who will benefit from such therapy, we need accurate diagnostic tools. ${ }^{21,22}$

\section{AMYLOID DEPOSITION AS A BIOLOGICAL MARKER OF AD}

In clinical practice, a definite diagnosis of $\mathrm{AD}$ is usually not possible owing to the requirement for histopathological examination. ${ }^{1}$ Moreover, owing to the heterogeneity of clinical manifestations and low specificity of the cognitive deficits, the diagnosis of $\mathrm{AD}$ can be challenging. ${ }^{23}$ Neuropathological studies that analyzed postmortem brain tissue found that the clinical diagnosis of $\mathrm{AD}$ is frequently inaccurate. ${ }^{24,25}$

Accumulation of the $\beta$-amyloid peptide in the brain is a hallmark of $\mathrm{AD} .^{26} \beta$-Amyloid is the product of sequential proteolytic cleavage of the amyloid precursor protein by $\beta$ - and $\gamma$-secretases. ${ }^{27}$ Senile plaques found in the brain of patients with $\mathrm{AD}$ are primarily composed of insoluble deposits of $\beta$-amyloid. ${ }^{28}$ Until recently, the investigation of amyloid deposition in living humans was limited because it used to rely on brain biopsy or postmortem examinations. Fortunately, in recent years, the development of radiopharmaceutical agents aimed at identifying amyloid deposition has allowed researchers to study in vivo amyloid deposition in humans. ${ }^{29}$ Briefly, amyloid imaging consists of an injection of a radiolabeled ligand targeting amyloid aggregates and use of positron emission tomography (PET) technology to acquire images of the brain in order to display foci of abnormal amyloid accumulation. ${ }^{29}$

Despite the recent development of this PET technology, radiolabeled biomarkers for amyloid imaging have already been used in several research studies. The vast majority of such investigations have employed Pittsburgh compound B labeled with carbon-11. These studies have shown that amyloid deposition: 1) occurs years before clinical dementia, ${ }^{30,31}$ 2) is related to cortical atrophy and cognitive decline, ${ }^{30-32} 3$ ) is more intense in patients with $\mathrm{MCI}$ who convert to $\mathrm{AD}$ than in nonconverters $^{33,34}$ and 4) plateaus when clinical dementia is established (while other neurodegenerative processes such as brain atrophy keep progressing). ${ }^{31,35}$ For the next few years, it is expected that the amount of information provided by amyloid imaging studies will sharply increase. For instance, this imaging modality is now used in a sub-study of the Alzheimer's Disease Neuroimaging Initiative, a large longitudinal (6-year) multicentric project in the USA involving cohorts of elderly controls and subjects with MCI and AD, aimed at validating neuroimaging and cerebrospinal fluid/ blood biomarkers for use in clinical trials of AD treatments. In this project, subjects are investigated with MRI and FDG-PET and then followed, thus allowing measurements of change in these biomarkers at different disease stages. ${ }^{36}$

Amyloid deposition is not pathognomonic of AD and, in fact, it is rather unspecific. For instance, it can be found in dementia with Lewy bodies and in cognitively intact elderly subjects. ${ }^{36,37}$ Therefore, a positive amyloid biomarker scan may have limited diagnostic value; on the other hand, a negative result from such a sensitive imaging test can be informative because amyloid deposition is a defining feature of $\mathrm{AD} .^{37,38}$ Thus, the immediate clinical usefulness of sensitive imaging biomarkers for brain amyloid deposition would be to rule out the presence of significant levels of $\beta$-amyloid in the brain. In other words, a negative result would mean that $\mathrm{AD}$ is an unlikely diagnosis. As an example, researchers showed that amyloid biomarkers could be useful to differentiate between $\mathrm{AD}$ and frontotemporal dementia. ${ }^{37,39,40}$

Amyloid imaging could also be useful as a non-invasive biomarker allowing a more adequate selection of subjects without overt dementia but with a high likelihood of progressing to $\mathrm{AD}$ in clinical trials of disease-modifying agents. ${ }^{21,41}$ Perhaps this imaging tool could even become useful to measure the efficacy of new drugs, ${ }^{42}$ as suggested by the results of a recent study that used amyloid imaging to quantify the reduction of $\beta$-amyloid load in patients treated with anti-amyloid antibody. ${ }^{43}$

One logistic concern is the short physical half-life of carbon-11, which prevents the applicability of Pittsburgh compound B-PET imaging to wider populations in clinical settings. This has raised interest in the development of amyloid imaging agents that can be labeled with fluorine-18 $\left({ }^{18} \mathrm{~F}\right)$, which has a longer decay half-life. Florbetapir (Amyvid $^{\mathrm{TM}}$ ) is one of the most promising of such agents, not only owing to the longer radioactive half-life of ${ }^{18} \mathrm{~F}$, but also because of the rapid kinetics and stable plateau of uptake of florbetapir in the brain following intravenous administration. ${ }^{44}$ These properties increase its potential availability and allow short post-dose waiting periods and flexibility in timing of image acquisition. ${ }^{44}$ Recent investigations have shown that ${ }^{18} \mathrm{~F}$-florbetapir PET imaging performed during life in a sample of elderly patients from hospice, long-term care and community healthcare facilities accurately predicted the presence of $\beta$-amyloid in the brain as verified at autopsy of the same subjects. ${ }^{45}$

In spite of the above advances, there are still important difficulties to be overcome before amyloid imaging with PET can be seen as a useful resource in clinical practice for the diagnostic work-up for dementia. Indeed, florbetapir has been rejected by a recent preliminary document of the United States Food and Drugs Administration (FDA), which highlighted the problem of inconsistent reader-to-reader image interpretation. ${ }^{46}$ This represents a set-back that will force the neuroimaging community to improve the reliability of amyloid imaging interpretations. 
The FDA document is based on the first phase 3 study focused on the relationship between florbetapir imaging and postmortem $\beta$-amyloid pathology. ${ }^{45}$ Results based on the binary classification (positive $\times$ negative) of the mean rating given by three trained nuclear medicine physicians resulted in an impressive 93\% sensitivity. ${ }^{45}$ However, the detailed FDA report pointed out that there was too much variation in the individual reader performance; for instance, one reader demonstrated an unacceptably low sensitivity of $55 \%$. Furthermore, "in over one-third of the subjects, at least one reader would have had a different binary interpretation of amyloid status from the other two readers". ${ }^{46}$ Based on the reader inconsistency, this document concluded that "the data did not produce evidence of clinical usefulness". ${ }^{46}$

So, what would be the next step?

One of the most relevant messages from the FDA document is the following: "The available data suggest that the variability in ${ }^{18} \mathrm{~F}$-florbetapir PET test results more likely stems from variability in image interpretation rather than image acquisition". ${ }^{46}$ In other words, if this imaging modality is one day to be widely used in clinical practice, then efforts should be focused on how to improve the reliability of imaging interpretation.

One way would be to improve the physicians' training, with lengthier and/or more sophisticated learning protocols. In real world clinical settings, this would not only be expensive but also limit the availability of this method to a few physicians and patients. An alternative would be to develop automated methods of image analysis that could help physicians make more accurate interpretations. Numerous results from recent years have provided evidence that automated techniques have a great potential to advance the diagnostic accuracy of neuroimaging methods for dementia and other neurological and psychiatric disorders.

\section{PATTERN CLASSIFICATION APPROACHES IN NEUROIMAGING STUDIES: FUTURE APPLICATIONS IN THE DIAGNOSIS OF DEMENTIA}

Neuropsychiatric researchers commonly perform betweengroup comparisons using neuroimaging data to obtain valuable insights into the neuropathological processes that underlie the diseases. The statistical methods of most of the studies cited in the sections above are based on this principle.

Nevertheless, such an approach cannot be used in clinical practice because neuroimaging techniques must provide reliable information of individual scans in order to be diagnostically useful. For this reason, researchers have recently developed computer-based, automated classification methods that analyze substantial amounts of information looking for a pattern that characterizes the disease. Then, the model can be tested for diagnostic accuracy. Methods for automated classification of brain imaging data can provide high accuracy in the evaluation of individual cases and for this reason, it has been recently suggested that such techniques could become established as useful diagnostic tools for clinical applications. ${ }^{47}$

For instance, these methods - also known as pattern classification approaches - have already been applied in MRI studies to differentiate:

- patients with AD from controls, with $87-95 \%$ accuracy ${ }^{48-51}$

- $\mathrm{AD}$ and frontotemporal lobar degeneration with $89 \%$ accuracy $^{49}$
- MCI from healthy controls, with 90\% accuracy ${ }^{52}$

- subjects with MCI who convert to AD and nonconver ters $\left(81 \%\right.$ accuracy) ${ }^{53}$

- children with and without autism (81\% accuracy) ${ }^{54}$

- patients with schizophrenia from controls (90\% accuracy). ${ }^{55}$

Pattern classification approaches have also been used in neurofunctional imaging studies designed to differentiate between patients with $\mathrm{AD}$ and controls, ${ }^{56} \mathrm{AD}$ and frontotemporal dementia, ${ }^{57}$ patients with schizophrenia and healthy subjects, ${ }^{58}$ schizophrenia and bipolar disorder ${ }^{59}$ and depression and controls. ${ }^{60}$ Moreover, these automated classifiers can be designed to combine multiple biomarkers (e.g. demographic data, structural and functional neuroimaging, genotyping information and laboratory results, such as cerebrospinal fluid biomarkers) in order to improve successful classification. ${ }^{61}$

Despite these recent findings, we are not aware of any study using pattern classification approaches to classify amyloid imaging data on an individual basis. Given the insufficient consistency in reader-to-reader interpretation of individual amyloid imaging data as pointed out by the recent FDA document discussed above, ${ }^{46}$ testing the accuracy of pattern classification methods in this neuroimaging modality seems a sensible next step.

\section{CONCLUSION}

Neuroimaging techniques have led to an increasingly large body of knowledge about AD by allowing the study of the brain in living subjects. These imaging methods are not only highly important research tools, but they are also commonly used in the evaluation of patients presenting with dementia in order to improve the accuracy of clinical diagnosis and identify brain lesions contributing to the cognitive decline. A recent major advance is the development of amyloid imaging techniques that allow in vivo identification of amyloid deposition in the brain. This imaging modality has already yielded important results and will likely determine an increase in the diagnostic accuracy of AD in the near future.

\section{REFERENCES}

1. McKhann G, Drachman D, Folstein M, Katzman R, Price D, Stadlan E. Clinical diagnosis of Alzheimer's disease: report of the NINCDSADRDA Work Group under the trivial auspices of Department of Health and Human Services Task Force on Alzheimer's Disease. Neurology. 1984;34:939-44.

2. Dubois B, Feldman HH, Jacova C, Dekosky ST, Barberger-Gateau P, Cummings J, et al. Research criteria for the diagnosis of Alzheimer's disease: revising the NINCDS-ADRDA criteria. Lancet Neurology. 2007;6:734-46, doi: 10.1016/S1474-4422(07)70178-3.

3. Busatto GF, Diniz BS, Zanetti MV. Voxel-based morphometry in Alzheimer's disease. Expert Rev Neurother. 2008;8:1691-702, doi: 10. 1586/14737175.8.11.1691.

4. Thompson PM, Hayashi KM, De Zubicaray GI, Janke AL, Rose SE, Semple J, et al. Mapping hippocampal and ventricular change in Alzheimer disease. Neuroimage. 2004;22:1754-66, doi: 10.1016/j.neuroimage. 2004.03.040.

5. McDonald CR, McEvoy LK, Gharapetian L, Fennema-Notestine C, Hagler DJ, Holland D, et al. Regional rates of neocortical atrophy from normal aging to early Alzheimer disease. Neurology. 2009;73:457-65, doi: 10.1212/WNL.0b013e3181b16431.

6. Whitwell JL, Przybelski SA, Weigand SD, Knopman DS, Boeve BF, Petersen $\mathrm{RC}$, et al. 3D maps from multiple MRI illustrate changing atrophy patterns as subjects progress from mild cognitive impairment to Alzheimer's disease. Brain. 2007;130 Pt 7:1777-86, doi: 10.1093/brain/ awm112. 
7. Braak E, Griffing K, Arai K, Bohl J, Bratzke H, Braak H. Neuropathology of Alzheimer's disease: what is new since A. Alzheimer? Eur Arch Psychiatry Clin Neurosci. 1999;249 Suppl 3:14-22.

8. Ferreira LK, Diniz BS, Forlenza OV, Busatto GF, Zanetti MV. Neurostructural predictors of Alzheimer's disease: a meta-analysis of VBM studies. Neurobiol Aging. 2009 [Epub ahead of print].

9. Schroeter M, Stein T, Maslowski N, Neumann J. Neural correlates of Alzheimer's disease and mild cognitive impairment: a systematic and quantitative meta-analysis involving 1351 patients. Neuroimage. 2009;47:1196-206, doi: 10.1016/j.neuroimage.2009.05.037.

10. Buchpiguel CA. PET e SPECT cerebrais na avaliação dos estados demenciais. Rev Bras Psiquiatr. 2001;23 Suppl I:36-7, doi: 10.1590/ S1516-44462001000500011.

11. Herholz K, Schopphoff H, Schmidt M, Mielke R, Eschner W, Scheidhauer $\mathrm{K}$, et al. Direct comparison of spatially normalized PET and SPECT scans in Alzheimer's disease. J Nucl Med. 2002;43:21-6.

12. Desai AK, Grossberg GT. Diagnosis and treatment of Alzheimer's disease. Neurology. 2005;64:S34-9.

13. Foster NL, Heidebrink JL, Clark CM, Jagust WJ, Arnold SE, Barbas NR, et al. FDG-PET improves accuracy in distinguishing frontotemporal dementia and Alzheimer's disease. Brain. 2007;130:2616-35, doi: 10.1093/ brain/awm177.

14. Waldemar G, Dubois B, Emre M, Georges J, McKeith IG, Rossor M, et al. Recommendations for the diagnosis and management of Alzheimer's disease and other disorders associated with dementia: EFNS guideline. Eur J Neurol. 2007;14:E1-26, doi: 10.1111/j.1468-1331.2006.01605.x.

15. Caroli A, Testa C, Geroldi C, Nobili F, Barnden LR, Guerra UP, et al. Cerebral perfusion correlates of conversion to Alzheimer's disease in amnestic mild cognitive impairment. J Neurol. 2007;254:1698-707, doi: 10. 1007/s00415-007-0631-7

16. Villain N, Desgranges B, Viader F, de la Sayette V, Mézenge F, Landeau B, et al. Relationships between hippocampal atrophy, white matter disruption, and gray matter hypometabolism in Alzheimer's disease. J Neurosci. 2008;28:6174-81, doi: 10.1523/JNEUROSCI.1392-08.2008.

17. Chaim TM, Duran FL, Uchida RR, Périco CA, de Castro CC, Busatto GF. Volumetric reduction of the corpus callosum in Alzheimer's disease in vivo as assessed with voxel-based morphometry. Psychiatry Res. 2007;154:59-68, doi: 10.1016/j.pscychresns.2006.04.003.

18. Chanraud S, Zahr N, Sullivan EV, Pfefferbaum A. MR diffusion tensor imaging: a window into white matter integrity of the working brain. Neuropsychol Ver. 2010;20:209-25, doi: 10.1007/s11065-010-9129-7.

19. Pievani M, Agosta F, Pagani E, Canu E, Sala S, Absinta M, et al. Assessment of white matter tract damage in mild cognitive impairment and Alzheimer's disease. Hum Brain Mapp. 2010;31:1862-75, doi: 10. 1002/hbm.20978.

20. Xie S, Xiao JX, Gong GL, Zang YF, Wang YH, Wu HK, et al. Voxel-based detection of white matter abnormalities in mild Alzheimer disease. Neurology. 2006;66:1845-9, doi: 10.1212/01.wnl.0000219625.77625.aa.

21. Aisen PS, Andrieu S, Sampaio C, Carrillo M, Khachaturian ZS, Dubois B, et al. Report of the task force on designing clinical trials in early (predementia) AD. Neurology. 2011;76:280-6, doi: 10.1212/WNL. 0b013e318207b1b9.

22. Cummings JL, Doody R, Clark C. Disease-modifying therapies for Alzheimer disease: challenges to early intervention. Neurology. 2007;69:1622-34, doi: 10.1212/01.wnl.0000295996.54210.69.

23. Löppönen M, Räihä I, Isoaho R, Vahlberg T, Kivelä SL. Diagnosing cognitive impairment and dementia in primary health care - a more active approach is needed. Age Ageing. 2003;32:606-12, doi: 10.1093/ ageing/afg097.

24. Mayeux R, Saunders AM, Shea S, Mirra S, Evans D, Roses AD, et al. Utility of the apolipoprotein E genotype in the diagnosis of Alzheimer's disease. Alzheimer's Disease Centers Consortium on Apolipoprotein E and Alzheimer's Disease. N Engl J Med. 1998;338:506-11.

25. Holmes C, Cairns N, Lantos P, Mann A. Validity of current clinical criteria for Alzheimer's disease, vascular dementia and dementia with Lewy bodies. Br J Psychiatry. 1999;174:45-50, doi: 10.1192/bjp.174.1.45.

26. Hardy J, Selkoe DJ. The amyloid hypothesis of Alzheimer's disease: progress and problems on the road to therapeutics. Science. 2002;297:3536, doi: 10.1126/science.1072994

27. Evin G, Weidemann A. Biogenesis and metabolism of Alzheimer's disease Abeta amyloid peptides. Peptides. 2002;23:1285-97, doi: 10.1016/ S0196-9781(02)00063-3.

28. Iwatsubo T, Odaka A, Suzuki N, Mizusawa H, Nukina N, Ihara Y. Visualization of A beta 42(43) and A beta 40 in senile plaques with end-specific A beta monoclonals: evidence that an initially deposited species is A beta 42(43). Neuron. 1994;13:45-53, doi: 10.1016/08966273(94)90458-8

29. Rabinovici GD, Jagust WJ. Amyloid imaging in aging and dementia: testing the amyloid hypothesis in vivo. Behav Neurol. 2009;21:117-28.

30. Chetelat G, Villemagne VL, Bourgeat P, Pike KE, Jones G, Ames D, et al. Relationship between atrophy and beta-amyloid deposition in Alzheimer disease. Ann Neurol. 2010;67:317-24.

31. Jack CRJr, Lowe VJ, Weigand SD, Wiste HJ, Senjem ML, Knopman DS, et al. Serial PIB and MRI in normal, mild cognitive impairment and
Alzheimer's disease: implications for sequence of pathological events in Alzheimer's disease. Brain. 2009;132:1355-65, doi: 10.1093/brain/ awp062.

32. Braskie MN, Klunder AD, Hayashi KM, Protas H, Kepe V, Miller KJ, et al Plaque and tangle imaging and cognition in normal aging and Alzheimer's disease. Neurobiol Aging. 2010;31:1669-78, doi: 10.1016/j. neurobiolaging.2008.09.012.

33. Forsberg A, Engler H, Almkvist O, Blomquist G, Hagman G, Wall A, et al. PET imaging of amyloid deposition in patients with mild cognitive impairment. Neurobiol Aging. 2008;29:1456-65, doi: 10.1016/j.neurobio laging.2007.03.029.

34. Koivunen J, Scheinin N, Virta JR, Aalto S, Vahlberg T, Någren K, et al Amyloid PET imaging in patients with mild cognitive impairment: a 2-year follow-up study. Neurology. 2011;76:1085-90, doi: 10.1212/WNL. 0b013e318212015e.

35. Engler H, Forsberg A, Almkvist O, Blomquist G, Larsson E, Savitcheva I, et al. Two-year follow-up of amyloid deposition in patients with Alzheimer's disease. Brain. 2006;129:2856-66, doi: 10.1093/brain/awl178.

36. Jagust WJ, Bandy D, Chen KW, Foster NL, Landau SM, Mathis CA, et al. The Alzheimer's Disease Neuroimaging Initiative positron emission tomography core. Alzheimers \& Dementia. 2010;6:221-9, doi: 10.1016/j. jalz.2010.03.003.

37. Rowe CC, Ng S, Ackermann U, Gong SJ, Pike K, Savage G, et al. Imaging beta-amyloid burden in aging and dementia. Neurology. 2007;68:171825, doi: 10.1212/01.wnl.0000261919.22630.ea.

38. Edison P, Rowe CC, Rinne JO, Ng S, Ahmed I, Kemppainen N, et al. Amyloid load in Parkinson's disease dementia and Lewy body dementia measured with [11C]PIB positron emission tomography. J Neurol Neurosurg Psychiatry. 2008;79:1331-8, doi: 10.1136/jnnp.2007.127878.

39. Engler H, Santillo AF, Wang SX, Lindau M, Savitcheva I, Nordberg A, et al. In vivo amyloid imaging with PET in frontotemporal dementia. Eur J Nucl Med Mol Imaging 2008;35:100-6, doi: 10.1007/s00259-0070523-1.

40. Drzezga A, Grimmer T, Henriksen G, Stangier I, Perneczky R, DiehlSchmid J, et al. Imaging of amyloid plaques and cerebral glucose metabolism in semantic dementia and Alzheimer's disease. Neuroimage. 2008;39:619-33, doi: 10.1016/j.neuroimage.2007.09.020.

41. Visser PJ, Knopman DS. Amyloid imaging in the prediction of Alzheimer-type dementia in subjects with amnestic MCI. Neurology. 2009;73:744-5, doi: 10.1212/WNL.0b013e3181b61b5d.

42. Wolk DA, Klunk W. Update on amyloid imaging: from healthy aging to Alzheimer's disease. Curr Neurol Neurosci Rep. 2009;9:345-52, doi: 10 1007/s11910-009-0051-4.

43. Rinne JO, Brooks DJ, Rossor MN, Fox NC, Bullock R, Klunk WE, et al. 11C-PiB PET assessment of change in fibrillar amyloid-beta load in patients with Alzheimer's disease treated with bapineuzumab: a phase 2 double-blind, placebo-controlled, ascending-dose study. Lancet Neurol. 2010;9:363-72, doi: 10.1016/S1474-4422(10)70043-0.

44. Wong DF, Rosenberg PB, Zhou Y, Kumar A, Raymont V, Ravert HT, et al. In vivo imaging of amyloid deposition in Alzheimer disease using the radioligand 18F-AV-45 (florbetapir [corrected] F 18). J Nucl Med. 2010;51:913-20, doi: 10.2967/jnumed.109.069088.

45. Clark CM, Schneider JA, Bedell BJ, Beach TG, Bilker WB, Mintun MA et al. Use of florbetapir-PET for imaging beta-amyloid pathology. JAMA. 2011;305:275-83, doi: 10.1001/jama.2010.2008

46. Food and Drug Administration - Peripheral and Central Nervous System Drugs Advisory Committee, US Department of Health \& Human Services. FDA Advisory Committee Briefing Document: New Drug Application 202-008 Amyvid ${ }^{\mathrm{TM}}$ (Florbetapir F 18 Injection), sponsored by Avid Radiopharmaceuticals. December 20, 2010. Available from: http://www.fda. gov/downloads/AdvisoryCommittees/CommitteesMeetingMaterials / Drugs/PeripheralandCentralNervousSystemDrugsAdvisoryCommittee/ UCM240265.pdf

47. Filipovych R, Davatzikos C, Initiative FtAsDN. Semi-supervised pattern classification of medical images: application to mild cognitive impairment (MCI). Neuroimage. 2011;55:1109-19, doi: 10.1016/j.neuroimage. 2010.12.066.

48. Duchesne S, Caroli A, Geroldi C, Barillot C, Frisoni GB, Collins DL. MRIbased automated computer classification of probable AD versus normal controls. IEEE Trans Med Imaging. 2008;27:509-20, doi: 10.1109/TMI. 2007.908685.

49. Klöppel S, Stonnington CM, Chu C, Draganski B, Scahill RI, Rohrer JD, et al. Automatic classification of MR scans in Alzheimer's disease. Brain 2008;131:681-9, doi: 10.1093/brain/awm319.

50. Oliveira PP, Nitrini R, Busatto G, Buchpiguel C, Sato JR, Amaro E. Use of SVM methods with surface-based cortical and volumetric subcortical measurements to detect Alzheimer's disease. J Alzheimers Dis. 2010;19:1263-72.

51. Vemuri P, Gunter JL, Senjem ML, Whitwell JL, Kantarci K, Knopman DS, et al. Alzheimer's disease diagnosis in individual subjects using structural MR images: validation studies. Neuroimage. 2008;39:1186-97, doi: 10.1016/j.neuroimage.2007.09.073.

52. Davatzikos C, Fan Y, Wu X, Shen D, Resnick SM. Detection of prodromal Alzheimer's disease via pattern classification of magnetic resonance 
imaging. Neurobiology Aging. 2008;29:514-23, doi: 10.1016/j.neurobiola ging.2006.11.010.

53. Misra C, Fan Y, Davatzikos C. Baseline and longitudinal patterns of brain atrophy in MCI patients, and their use in prediction of short-term conversion to AD: results from ADNI. Neuroimage. 2009;44:1415-22, doi: 10.1016/j.neuroimage.2008.10.031.

54. Ecker C, Rocha-Rego V, Johnston P, Mourao-Miranda J, Marquand A, Daly EM, et al. Investigating the predictive value of whole-brain structural MR scans in autism: a pattern classification approach. Neuroimage. 2010;49:44-56, doi: 10.1016/j.neuroimage.2009.08.024.

55. Fan Y, Shen D, Gur RC, Gur RE, Davatzikos C. COMPARE: classification of morphological patterns using adaptive regional elements. IEEE Trans Med Imaging. 2007;26:93-105, doi: 10.1109/TMI.2006.886812.

56. Chaves R, Ramirez J, Gorriz JM, Lopez M, Salas-Gonzalez D, Alvarez I, et al. SVM-based computer-aided diagnosis of the Alzheimer's disease using t-test NMSE feature selection with feature correlation weighting. Neurosci Lett. 2009;461:293-7, doi: 10.1016/j.neulet.2009.06.052.

57. Horn JF, Habert MO, Kas A, Malek Z, Maksud P, Lacomblez L, et al. Differential automatic diagnosis between Alzheimer's disease and frontotemporal dementia based on perfusion SPECT images. Artif Intell Med. 2009;47:147-58, doi: 10.1016/j.artmed.2009.05.001.

58. Shen H, Wang L, Liu Y, Hu D. Discriminative analysis of resting-state functional connectivity patterns of schizophrenia using low dimensional embedding of fMRI. Neuroimage. 2010;49:3110-21, doi: 10.1016/j.neuro image.2009.11.011.

59. Costafreda SG, Fu CH, Picchioni M, Toulopoulou T, McDonald C, Kravariti E, et al. Pattern of neural responses to verbal fluency shows diagnostic specificity for schizophrenia and bipolar disorder. BMC Psychiatry. 2011;11:18, doi: 10.1186/1471-244X-11-18.

60. Fu CH, Mourao-Miranda J, Costafreda SG, Khanna A, Marquand AF, Williams SC, et al. Pattern classification of sad facial processing. toward the development of neurobiological markers in depression. Biol Psychiatry. 2008;63:656-62, doi: 10.1016/j.biopsych.2007.08. 020 .

61. Kohannim O, Hua X, Hibar DP, Lee S, Chou YY, Toga AW, et al Boosting power for clinical trials using classifiers based on multiple biomarkers. Neurobiol Aging. 2010;31:1429-42, doi: 10.1016/j.neurobiolaging.2010.04.022. 